\section{Brightness discrimination learning in posterior neodecorticated and normal hooded rats*}

\author{
BRUCE L. BIRD and LOIS O. STRATTON \\ Louisiana State University in New Orleans, New Orleans, La. 70122
}

Normal hooded rats were superior to posterior operates on acquisition of a simultaneous brightness problem. Acquisition of a subsequent successive problem showed that operates had improved significantly but were still inferior to normals. Both normals and operates learned the simultaneous problem faster when a dark stimulus was the positive cue; however, free choice preference for the dark was demonstrated in normal Ss only. Effects of preference and perceptual factors on learning are discussed.

The finding that posteriorly ablated rats learn a brightness discrimination as effectively as normals has recently been questioned (Horel et al, 1966; Spear \& Braun, 1969). Hooded rats exhibit reduced light aversion after posterior neodecortication in a free choice preference situation (Altman, 1962), and this explains their initial superior performance on light-dark discriminations when the positive cue is the brighter of two stimuli (Altman, 1962). Stratton \& Edwards (1971) reported that albinos, in contrast to hooded rats, showed no significant reduction in light aversion after posterior neodecortication, and albinos approaching a high-intensity light in a T-maze were impaired in learning a simultaneous brightness discrimination. The following two studies evaluated the light-dark preference of normal and posterior hooded rats and the effect on learning two discriminations based on flux cues.

\section{EXPERIMENT 1}

Subjects and Apparatus

The Ss were 28 male hooded rats, 100-120 days old at the time of testing. Fourteen Ss were assigned randomly to either a high- (Hi) or low(Lo) intensity light group. The Ss were tested in a Plexiglas-enclosed T-maze described by Stratton \& Edwards (1971). Intensity readings (using a Grossen tri-lux footcandle meter calibrated at rat eye level) indicated 1.2 fc (Lo) and 16-18 fc (Hi) for the lighted section and 0 fc for the dark section of the maze.

Procedure

The Ss were preference tested $5 \mathrm{~min}$ a day for 6 days with room lights off and one or the other section illuminated according to a Gellerman series. The Ss were placed in the center of the T-maze, and time spent in the

*We thank the LSUNO Department of Psychology and Dr. S. T. Elder for support of this research. We are also indebted to Dr. James May, Carolyn Wagner, and E. J Freymark for their help in preparation of the manuscript and illustrations. light and dark arms was recorded as well as the number of crossings from one section to the other. Time spent in front of the startbox was regarded as neutral. After preference testing was completed, room lights were turned on and apparatus lights off, and Ss were trained to open goalbox (GB) doors in preparation for Experiment 2.

All Ss received bilateral position neodecortication by the suction method, under sodium nembutal anesthesia. Postmortum histological examinations revealed that Kreig's (1946) Areas 17, 18, 18a, parts of 7 and 36 , and the underlying white matter were removed (see Fig. 1). Operates were given 3 weeks to recover, after which they were retested for preference using the same procedures.

\section{Results}

A Ss over Level by Operation by was performed on time in seconds in light and dark. Time in light and dark was treated as a repeated measure. A significant Operation by Stimulus interaction showed that light was significantly avoided by normals ( $\bar{X} \mathrm{DK}=126.3 ; \overline{\mathrm{X}} \mathrm{LT}=105.1$; $p<.05$ ), whereas posteriors had no significant preference for light or dark ( $\overline{\mathrm{X}} \mathrm{DK}=125.5 ; \quad \overline{\mathrm{X}} \mathrm{LT}=122.34$ ). An operation main effect showed that posteriors spent more time in the neutral area than did normals ( $\bar{X}$ for posteriors $=123.9 ; \overline{\mathrm{X}}$ for normals $=$ $115.7 ; \mathrm{p}<.01)$. A Ss over Operation by Days analysis of variance showed that posteriors crossed from one arm to the other significantly more than did normals ( $\bar{X}$ for posteriors $=11.04$; $\bar{X}$ for normals $=8.34 ; p<.01)$, and the crossing activity of posteriors varied over days $(9.8,12.0,11.7,11.4$, $11.0,10.2 ; \mathrm{p}<.01$ ), while remaining constant for normals $(8.9,7.7,8.0$, 8.1, 8.7, 8.6)

\section{EXPERIMENT 2}

Subjects

The Ss were the 28 rats from Stimulus by Days analysis of variance Experiment 1 and 28 additional normal hooded rats, all 130-140 days old at the time of testing. The $\mathrm{Hi}$ and Lo light level posterior Ss were randomly split into two groups of 7 each. One group at each level was assigned to light (LT) as the positive stimulus and the other group to dark (DK). Normals were assigned randomly to four similar groups: HiLT, HiDK, LoLT, LoDK.

\section{Procedure}

Operates were retrained to open GB doors, and normals (after 6 days of maze exposure similar to preference testing) were pretrained to open GB doors as described in Experiment 1. After pretraining, all Ss were given six trials a day on a simultaneous (SI) discrimination with the positive stimulus alternated according to a Gellerman series. A response to the positive stimulus admitted the $S$ to the $G B$, while a response to the negative stimulus resulted in footshock and confrontation with a locked GB door. An error was recorded when the S's foot contacted the negative GB grid. Learning criterion was $11 / 12$ errorless trials. The Ss were given 5 days of



Fig. 1. Representative posterior neocortical lesions including deepest (lower right) and smallest lesion (upper right). 


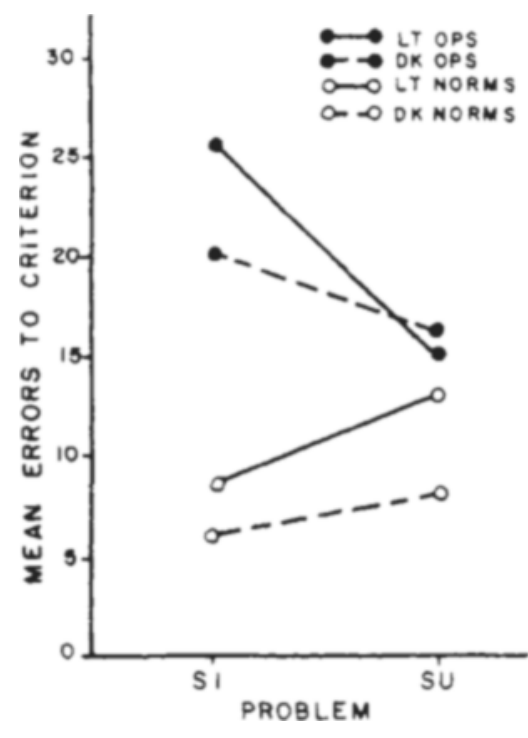

Fig. 2. Mean errors to criterion for dark (DK) and light (LT) positive normals (NORMS) and operates (OPS) on simultaneous (SI) and successive (SU) brightness problems.

overtraining on SI, then were switched to a successive (SU) brightness discrimination. The SI light level was maintained for each $S$, but now both maze arms LT signaled right $G B$ positive and both arms DK signaled left GB positive. The Ss were again trained to an $11 / 12$ criterion.

\section{Results}

A Ss over Operation by Level by Stimulus by Problem analysis of variance was performed on errors and on trials to criterion. Main effects and interaction effects for light level were not significant. Trials and errors yielded similar effects, with the exception of main effects for SI vs SU in which trials revealed no differences, but error differences were significant $(\mathrm{SI}=15.3 ; \mathrm{SU}=13.2 ; \mathrm{p}<.05)$. Only errors data are subsequently reported.

Figure 2 shows that posteriors did more poorly than normals on both problems $(p<.01)$ and that LT positive Ss made more errors than did DK positive Ss $(p<.05)$. The Operation by Problem interaction showed that posteriors were better on SU than on SI, but normals were better on SI than on SU $(p<.01)$. The Operation by Problem by Stimulus interaction revealed that $\mathrm{LT}$ positive posteriors made more errors than did DK positive posteriors on SI, but there were no significant differences on SU. Normal LT rats made more errors than did DK rats ( $p<.05$, see Fig. 2 ). Plotting mean errors over days showed an effect similar to that of Horel et al (1966) and Spear \& Braun (1969). The SI LT normals began learning impaired by their $\mathrm{LT}$ aversiveness but overcame it after Day 1 (Fig. 3). Posteriors had no stimulus preference during the first 3 days of learning, and DK posteriors improved more rapidly than did L'T posteriors after Day 3.

\section{DISCUSSION}

The superior learning of normals over operates suggests that posterior Ss incurred a learning deficit related to the perception of cues signaling choice behavior. Lashley (1935) reported that posteriors suffer a moderate loss in difference threshold, and it's well known that they have defective pattern vision (Lashley, 1931). Posteriors demonstrated increased maze activity which is characteristic of peripherally blinded Ss (Glickman, 1958). In addition, cortical ablation produces losses of the attention and alerting aspects of behavior (Krechevsky, 1936; Thompson, 1965). The data from Experiment 2 showed that operates were significantly improved on the second postoperative problem. Apparently, posterior Ss overcame some incompetence while learning the first problem which transferred to the second problem, bringing them closer to the performance scores of normal Ss. The fact that posterior Ss had ablations of the visual neocortex suggests that the regained competence was a perceptual ability to attend to and utilize visual cues. The perception deficit hypothesis is attractive because it postulates concomitant sensory and attention losses on the supposition that posteriors must relearn to attend to visual cues with their remaining sensory apparatus. An alternate interpretation, that SU was an easier problem, is unlikely, since Bauer \& Cooper (1964) and unpublished data from this laboratory have shown that posteriors have great difficulty in learning SU and make numerous errors to criterion.

Hooded rats' preferences for the dark was abolished by posterior neodecortication at both differential levels of illumination. This concurs with findings of Horel (1966), Altman (1962), and Spear \& Braun (1969). However, operates were impaired in learning a luminous flux discrimination, and light-positive Ss did more poorly than dark-positive Ss. Several factors indicate that photic preference did not contribute significantly to the performance decrement of posteriors. First, dark. and light-positive posteriors performed equally well during the first 3 days of learning. Second, there were no learning or preference differences between high- and low-illumination posterior groups. Third, preference testing revealed no differences in time spent in dark vs light sectors of the maze.

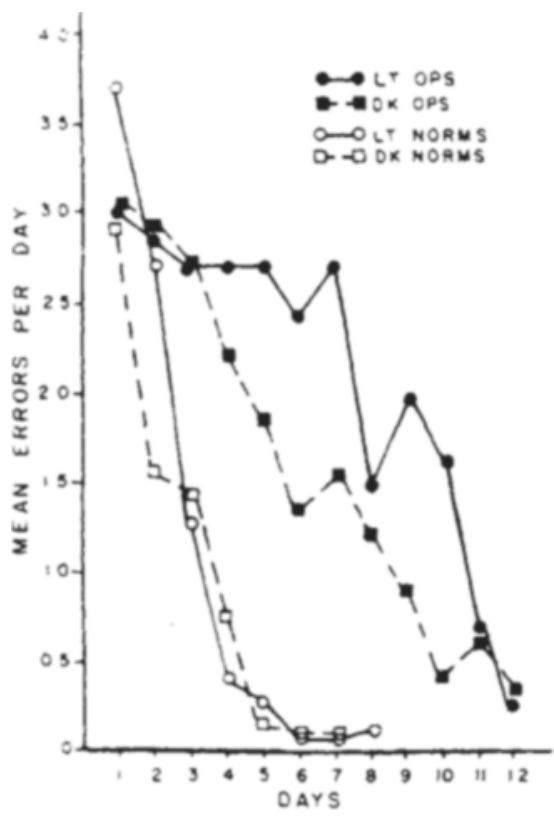

Fig. 3. Mean daily errors for light (LT) and dark (DK) positive operates (OPS) and normals (NORMS) on simultaneous brightness problems.

Attention models (Zeaman \& House, 1963; Lovejoy, 1968) state that learning based on a specific relevant cue depends upon the relative saliency of that cue in the overall population of available cues. Harlow (1959) proposed that the correct response to a discrimination will not appear until erroneous response tendencies are suppressed. In the present experiment, the light stimulus situated in an otherwise darkened room was the most salient differential cue, so erroneous responses toward the light could be more easily suppressed than errors toward the dark, less salient cue. This may explain why dark-positive operates and normals learned more quickly than light-positive Ss. Dark approaching normals performed better on both SI and $\mathrm{SU}$, indicating that they also found the light avoidance problem easier than the dark avoidance problem, and this learning ability transferred to SU.

Reduced light aversion found in hooded rats after posterior ablation was not apparent in posterior albino rats (Stratton \& Edwards, 1971). Thus, caution should be exercised in making comparisons across subspecies especially with regard to the mutant albino. The albino's aversion to light is undoubtedly due to inability to attenuate light passing through the colorless iris (Chorover \& Chase, 1968). Perceptual deficits best explain the retarded performance of posterior hooded rats, while light aversion is a primary consideration in evaluating 
the behavior of albino rats.

\section{REFERENCES}

ALTMAN, J. Etfects of lesions in central nerous risual structures on light aversion in rats. American Joumal of Physiology, 1962. 202,1206-1210.

BAUER. J. H., \& COOPER, R. M. Effects of posterior cortical lesions on performance of a brightness discrimination task. Journal of Comparative \& Physiological Psychology, 1964, 58, 84-92.

CHOROVER, S. L., \& CHASE, R. Persistence of visual pattern discrimination in binocularly-occluded albino rats. Journal of Comparative \& Physiological Psychology, 1968, 65, 238-245

GLICKMAN, S. E. Effects of peripheral blindness on exploratory behavior in the hooded rat. Journal of Psychology, 1958 , $12,45-51$

HARLOW, H. F. Learning set and error factor theory. In $S$. Koch (Ed.),
Psychology: A study of a science. Tol. II. New York: McGraw-Hill, 1959.

HOREL, J. A., BETTINGER, L. A., ROYCE. J. C.. \& MEYER, D. R. Role of the neocortex in the leaming and releaming of two visual habits by the rat. Joumal of Comparative \& Physiological Psychology, 1966,61, 66-78.

KRECHEVSKY. I. Brain mechanisms and brightness discrimination learning. Joumal of Comparative Psychology. 1936. $21,404-445$.

KREIG, W. J.S. Connections of the cerebral cortex: 1. The albino rat: A. Topography of the cortical areas. Joumal of Comparative Neurology, 1946,84 . Comparat

LASHLEY, K. S. The mechanism of vision IV: The cerebral areas necessary for pattern vision in the rat. Journal of Comparative Neurology. 1931, 53, 417.

L ASHLEY, K. S. The mechanism of vision. XII: Nervous structures based on reactions to light. Comparative psychology Monographs. 1935, 11
43-79.

LOVEJOY, E. Attention in discrimination learning. San Francisco: Holden-Day. 1968.

SPEAR. P. D. B BRAUN, J.J Sonequivalence of normal and posterioriy neodecorticated rats on two brightness discrimination problems. Journal of Comparative \& Physiological Psychology, 1969,67,235-239.

STRATTON. L. O.. \& EDWARDS, s. Preference and sensory factors in brightness discrimination leaming of posterior neodecorticated albino rats. Psychonomic Science, 1971. 24, 9-10.

THOMPSON, R. F. The neural basis of stimulus generalization. In D. Mostofsky (Ed.), Stimulus generalization. Stanford: Stanford University Press, 1965.

ZEAMAN, D., \& HOUSE, B. J. The role of attention in retardate discrimination learning. In N. K. Ellis (Ed.) Handbook of mental deficiency: Psichological theory and research, New York: McGraw-Hill, 1963 . 